\title{
Different uptake of gentamicin through TRPV1 and TRPV4 channels determines cochlear hair cell vulnerability
}

\author{
Jeong-Han Lee ${ }^{1,2}$, Channy Park ${ }^{1,3}$, Se-Jin Kim, Hyung-Jin Kim, Gi-Su Oh, AiHua Shen, \\ Hong-Seob So and Raekil Park
}

Hair cells at the base of the cochlea appear to be more susceptible to damage by the aminoglycoside gentamicin than those at the apex. However, the mechanism of base-to-apex gradient ototoxicity by gentamicin remains to be elucidated. We report here that gentamicin caused rodent cochlear hair cell damages in a time- and dose-dependent manner. Hair cells at the basal turn were more vulnerable to gentamicin than those at the apical turn. Gentamicin-conjugated Texas Red (GTTR) uptake was predominant in basal turn hair cells in neonatal rats. Transient receptor potential vanilloid 1 (TRPV1) and 4 (TRPV4) expression was confirmed in the cuticular plate, stereocilia and hair cell body of inner hair cells and outer hair cells. The involvement of TRPV1 and TRPV4 in gentamicin trafficking of hair cells was confirmed by exogenous calcium treatment and TRPV inhibitors, including gadolinium and ruthenium red, which resulted in markedly inhibited GTTR uptake and gentamicin-induced hair cell damage in rodent and zebrafish ototoxic model systems. These results indicate that the cytotoxic vulnerability of cochlear hair cells in the basal turn to gentamicin may depend on effective uptake of the drug, which was, in part, mediated by the TRPV1 and TRPV4 proteins.

Experimental \& Molecular Medicine (2013) 45, e12; doi:10.1038/emm.2013.25; published online 8 March 2013

Keywords: gentamicin; hair cells; ototoxicity; TRPV1; TRPV4

\section{INTRODUCTION}

Aminoglycoside antibiotics such as gentamicin are a class of polybasic compounds used for Gram-negative bacterial infections. Rapid uptake and long exposure of the cochlea to gentamicin accounts for the development of ototoxicity as assessed by cochlear hair cell death. Interestingly, hair cells at the base of the cochlea appear to be more susceptible to damage by gentamicin than those at the apex. Degradation of three rows of outer hair cells (OHCs) and a single row of inner hair cells (IHCs) due to gentamicin progresses in a base-toapex gradient. ${ }^{1-3}$ However, the exact mechanisms of how gentamicin causes the base-to-apex gradient ototoxicity and how the base-to-apex gradient ototoxicity is associated with entrance of gentamicin into the IHCs and OHCs of the cochlea in vivo are not understood. The base-to-apex gradient of aminoglycoside ototoxicity can be, in part, attributed to the difference of intrinsic susceptibility of cochlea to aminoglycosides. Considering that hair cells at the basal turn are severely affected, whereas hair cells at the apex are not affected when exposed to an equal amount of aminoglycosides, ${ }^{1,3}$ a particular underlying difference in intrinsic susceptibility toward drugs may exist. Interestingly, Sha et al. ${ }^{4}$ supported this possibility by demonstrating that the levels of reduced glutathione, a critical reactive oxygen species scavenger, are higher at the apex than those of OHCs at the base; thereby, OHCs at the apex are intrinsically more resistant

Vestibulocochlear Research Center, Center for Metabolic Function Regulation and Department of Microbiology, Wonkwang University School of Medicine, Iksan, Jeonbuk, South Korea

Correspondence: Professor H-S So, Department of Microbiology, Wonkwang University School of Medicine, 344-7 Shinyong-dong, Iksan, Jeonbuk 570-749, South Korea.

E-mail: jeanso@wku.ac.kr

or Professor R Park, Department of Microbiology, Wonkwang University School of Medicine, 344-2 Shinyong-dong, Iksan, Jeonbuk 570-749, South Korea. E-mail: rkpark@wku.ac.kr

${ }^{1}$ These two authors contributed equally to this work.

2Present address: Center for Neuroscience, Department of Anesthesiology and Pain Medicine, Program in Communication Science, School of Medicine, University of California, Davis, Davis, CA, USA.

${ }^{3}$ Present address: Division of Cell Biology and Genetics, House Research Institute, Los Angeles, CA, USA.

Received 12 December 2012; accepted 9 January 2013 
to free-radical damage than those at the base. However, there may be a difference of gentamicin uptake by hair cells at the basal or apical turn of the cochlea, and this difference may affect the susceptibility of hair cells to gentamicin leading to the base-to-apex gradient ototoxicity.

It has been proposed that endocytosis is one of the mechanisms of aminoglycoside uptake at the hair cell apical membrane. ${ }^{5,6}$ Internalized aminoglycosides are transported to lysosomes where they accumulate and cause hair cell apoptosis over time. ${ }^{7}$ In general, endocytosis is temperature dependent in euthermic birds and mammals and slows down at hypothermic temperatures. ${ }^{8}$ However, rapid aminoglycoside uptake and toxicity occur at room temperature and also at $4{ }^{\circ} \mathrm{C}$ in vitro, ${ }^{9-11}$ further supporting the possibility that aminoglycosides permeate through nonselective cation channels. This likely involves transient receptor potential (TRP) cation channels of the subfamily V, such as TRP vanilloid 1 (TRPV1) and TRP vanilloid 2 (TRPV4) because regulators of these channels modulate aminoglycoside uptake. $^{11,12}$

Although zebrafish do not contain a cochlea or outer ear, ${ }^{13,14}$ hair cells in zebrafish neuromasts, which are similar in structure and function to the inner ear hair cells in mammals, perform vestibular and auditory functions. ${ }^{15,16}$ The neuromasts are arranged in a stereotypical pattern along the anterior lateral lines of the head, body and posterior lateral lines of the tail. Live hair cells can be visualized easily in vivo in transparent embryos by staining with 2-(4-(dimethylamino)styryl)- $N$-ethylpyridinium iodide (DASPEI), a fluorescent styryl dye. ${ }^{17-19}$ The optical clarity of the zebrafish provides advantages for high-throughput morphological and functional analyses of hair cells following drug treatment.

The use of gentamicin conjugated to fluorescent Texas Red (GTTR) shows the intracellular localization of this aminoglycoside in endosomes, endoplasmic reticulum, Golgi bodies, mitochondria, hair cell nuclei and also diffusely in the kidney tubule cell cytoplasm. ${ }^{10,11,20}$

We hypothesized that a gentamicin uptake difference in hair cells occurs depending on the location of these cells from the base to apex, and that this difference causes base-to-apex gradient ototoxicity. Thus, in this study, we examined how and how much aminoglycoside is transported into hair cells using GTTR as a probe in rodent and zebrafish models. We demonstrated that TRPV1 and TRPV4 channels in hair cells are involved in the aminoglycoside uptake gradient and that the difference in gentamicin uptake by hair cells at the basal and apical turn of the cochlea caused base-to-apex gradient ototoxicity.

\section{MATERIALS AND METHODS}

\section{Reagents}

Gentamicin, 4',6-diamidino-2-phenylindole (DAPI), phalloidintetramethylrhodamine isothiocyanate (TRITC), and phalloidinfluorescein isothiocyanate (FITC) were purchased from Sigma Chemical (St Louis, MO, USA). Four-well culture dishes were purchased from NUNC (Roskilde, Denmark). Dulbecco's modified essential medium, fetal bovine serum, YO-PRO-1, DASPEI, Alexa Fluor 488-conjugated donkey anti-goat, Alexa Fluor 568-conjugated goat anti-rabbit and Texas Red (TR) were obtained from Invitrogen (Carlsbad, CA, USA). The anti-TRPV1 and anti- $\beta$-actin antibodies were purchased from Santa Cruz Biotechnology (Santa Cruz, CA, USA). Anti-TRPV4 was obtained from Abcam (Cambridge, MA, USA).

\section{Organotypic cochlear cultures}

Sprague-Dawley (SD) rats were killed on postnatal day 3 (P3), and the temporal bones were isolated in a sterile manner. ${ }^{21}$ After placing the tissue in 6-cm dishes with ice-cold phosphate-buffered saline (PBS, $\mathrm{pH}$ 7.4), the cochlear capsule peeled off, and the membranous labyrinth was exposed. The spiral ligament and stria vascularis were removed, and the organ of Corti was dissected under a microscope. Two types of cochlear explants were prepared for this experiment. One was a three-part cochlear explant, including the apex, middle and base. The other type was the whole turn explant without the modiolus. Each explant was placed on a glass coverslip in a fourwell dish. These explants contained the organ of Corti, spiral limbus, spiral ganglion neurons and modiolus. The cochlear explants were treated with high-glucose Dulbecco's modified essential medium containing $10 \%$ heat-inactivated fetal bovine serum with or without $300 \mu \mathrm{M}$ gentamicin and incubated for $24 \mathrm{~h}$ at $37^{\circ} \mathrm{C}$ under $5 \% \mathrm{CO}_{2}$.

\section{Phalloidin staining}

At the end of the experiment, the cochlear explants were fixed with $4 \%$ paraformaldehyde (PFA) in PBS at room temperature for $30 \mathrm{~min}$, washed with PBS and incubated with $0.1 \%$ Triton X-100 (Sigma) at room temperature for $15 \mathrm{~min}$. They were stained with TRITC-labeled phalloidin (1:3000; Sigma P1951) for 30 min in the dark. After rinsing three times with PBS, the specimens were further stained with DAPI for $10 \mathrm{~min}$ in the dark and then observed under a fluorescence microscope. Morphologically intact hair cells were counted in a section corresponding to 10 IHCs at three different zones located at the apical, middle and basal turns of each organ of Corti.

\section{Gentamicin-Texas Red conjugation and in vivo injection}

GTTR was prepared as described previously. ${ }^{10}$ Gentamicin sulfate (Sigma; $50 \mathrm{mg} \mathrm{ml}^{-1}$ in $\mathrm{K}_{2} \mathrm{CO}_{3}, \mathrm{pH}$ 9.0) and succinimidyl esters of Texas Red (Invitrogen; $2 \mathrm{mg} \mathrm{ml}^{-1}$ in dimethyl formamide) were agitated together at $4{ }^{\circ} \mathrm{C}$ for 3 days to produce GTTR. Neonatal SD rats were used to examine in vivo uptake of gentamicin into cochlea. P3 rats were injected subcutaneously with a single $300 \mathrm{mg} \mathrm{kg}^{-1}$ dose of GTTR solution (including unconjugated gentamicin) and were allowed to recover for $24 \mathrm{~h}$. Several P3 rats received a subsequent GTTR injection at 24,48 and $72 \mathrm{~h}$ after the initial injection and were allowed to recover for $24 \mathrm{~h}$. P3 control rats were injected with TR at the same volumes and concentration equivalents, and the animals were allowed to recover for $24 \mathrm{~h}$. This experimental protocol was approved by the Animal Care and Use Committee at the Wonkwang University School of Medicine.

\section{Paraffin embedding for cultured organ of Corti}

To prepare gels, $18 \mu \mathrm{l}$ of bovine collagen type I (BD Biosciences, San Diego, CA, USA) was added to $2 \mu \mathrm{l} 10 \times$ Hanks' balanced salt solution and $2 \mu \mathrm{l} \mathrm{NaOH}$ in a tube on ice. The solution was mixed with a pipette, and $22 \mu \mathrm{l}$ was added to a coverglass. The matrix was given $30 \mathrm{~min}$ to gel at $37^{\circ} \mathrm{C}$ under $5 \% \mathrm{CO} 2$, and media were added. 
After culturing the cochlear explants on a thin collagen matrix, the specimens were washed with PBS and fixed with 4\% PFA for $15 \mathrm{~min}$. The specimens were then dehydrated and embedded in paraffin. Sections of $4 \mu \mathrm{m}$ thickness were deparaffinized in xylene and rehydrated through a graded ethanol. Specimens were further incubated with DAPI in PBS for $10 \mathrm{~min}$ for nuclear staining and then mounted.

\section{Tissue fixation and immunohistochemical studies}

Animals were deeply anesthetized at specific time points (24, 48 and $72 \mathrm{~h}$ ) following the initial GTTR injection to measure in vivo gentamicin uptake and for immunohistochemical studies. The temporal bones were removed and fixed in 4\% PFA in PBS overnight at $4{ }^{\circ} \mathrm{C}$ as described previously..$^{22}$ The temporal bones were decalcified by incubation in $10 \%$ EDTA at $4{ }^{\circ} \mathrm{C}$ for 2 weeks. The EDTA solution was changed daily. The bones were then dehydrated and embedded in paraffin. Sections of $4 \mu \mathrm{m}$ thickness were deparaffinized in xylene and rehydrated through graded concentrations of ethanol. Specimens were further incubated with DAPI in PBS for 10 min for nuclear staining. These specimens were directly examined under a fluorescent microscope to assess in vivo gentamicin uptake into the cochlea. Endogenous peroxidase was blocked with $3 \%$ hydrogen peroxide for $5 \mathrm{~min}$ at room temperature for the TRPV1 and TRPV4 immunochemical studies. Then, the sections were washed in Trisbuffered saline and nonspecific binding was blocked with $1 \%$ bovine serum albumin for $1 \mathrm{~h}$. The primary antibody (1:200) was added to the slides and incubated overnight at $4{ }^{\circ} \mathrm{C}$. After the incubation with the primary antibodies including anti-TRPV1 and anti-TRPV4, the slides were washed three times with Tris-buffered saline plus $0.05 \%$ Tween-20 and incubated with secondary antibodies for $1 \mathrm{~h}$ at room temperature in the dark. We used Alexa Fluor 488-conjugated donkey anti-goat or Alexa Fluor 568-conjugated goat anti-rabbit as the secondary antibodies (Invitrogen) in a dilution of 1:500. The slides were then examined under a fluorescent microscope (X71, Olympus, Tokyo, Japan). In addition, the decalcified cochlear bone was removed using fine forceps to make surface preparation, followed by removal of the lateral wall, stria vascularis, Reissner's membrane and tectorial membrane. The whole cochlea was stained with phalloidin-FITC and observed under a fluorescent microscope.

TRPV1 and TRPV4 immunofluorescence in cochlear culture Cochlear explants were washed twice with ice-cold PBS and fixed with $4 \%$ PFA in PBS for $15 \mathrm{~min}$ at room temperature after removing the culture medium. Samples were then rinsed twice with PBS, blocked in a blocking solution containing $5 \%$ goat serum and $0.1 \%$ Triton X-100 and then incubated with primary anti-TRPV1 and anti-TRPV4 antibodies in a solution containing $3 \%$ goat serum and $0.1 \%$ Triton $\mathrm{X}-100$ overnight at $4{ }^{\circ} \mathrm{C}$. After three washes with PBS, the samples were incubated for $2 \mathrm{~h}$ with Alexa Fluor 488-conjugated donkey anti-goat secondary antibody for TRPV1 and with Alexa fluor 568conjugaed goat anti-rabbit antibody for TRPV4 in a dilution of 1:500. Samples were then washed with PBS and mounted. Images were observed under a fluorescent microscope equipped with a digital camera (IX71, Olympus). Fluorescent images were captured using appropriate filters.

\section{Reverse transcriptase-PCR amplification}

Total cellular RNA was extracted from whole cochleae using TRIzol reagent (Invitrogen) according to the manufacturer's protocol. Complementary DNA was synthesized from total RNA $(1 \mu \mathrm{g})$.
Then, 35 PCR cycles with Taq DNA polymerase (Takara, Takara Shuzo, Kyoto, Japan) were performed. The gene-specific primer sequences were as follows: TRPV1 (forward, $5^{\prime}$-TGACTACCGGTGGT GTTTCA- $3^{\prime}$ and reverse, 5'-TGATCCCTGCATAGTGTCCA- $3^{\prime}$ ) TRPV4 (forward, 5'-ATCAACTCGCCCTTCAGAGA-3' and reverse, $5^{\prime}$-GGTGTTCTCTCGGGTGTTGT- $3^{\prime}$ ) and GAPDH (forward, 5'-GC ACCCCTGGCCAAGG- $3^{\prime}$ and reverse, $5^{\prime}$-GGCCTCCAAGGAGTAA G- $\left.3^{\prime}\right)$. The predicted size of the amplicon was $330 \mathrm{bp}$ for TRPV1 and $339 \mathrm{bp}$ for TRPV4.

\section{Gentamicin uptake in zebrafish}

Wild type zebrafish ( $\mathrm{AB}$ line) were maintained at $28.5^{\circ} \mathrm{C}$ on a $14 \mathrm{~h}$ light $/ 10 \mathrm{~h}$ dark cycle. ${ }^{23}$ All embryos were generated by natural pair-wise mating and staged as described previously. ${ }^{24}$ The 5 -dayold zebrafish were treated with gentamicin added directly to the embryonic medium (EM; $13.7 \mathrm{~mm} \mathrm{NaCl}, 540 \mu \mathrm{M} \mathrm{KCl} \mathrm{(pH} \mathrm{7.4),} 25 \mu \mathrm{M}$ $\mathrm{Na}_{2} \mathrm{HPO}_{4}, 44 \mu \mathrm{M} \mathrm{KH}_{2} \mathrm{PO}_{4}, 300 \mu \mathrm{M} \mathrm{CaCl}_{2}, 100 \mu \mathrm{M} \mathrm{MgSO}$ and $420 \mu \mathrm{M}$ $\left.\mathrm{NaHCO}_{3}(\mathrm{pH} 7.4)\right) .{ }^{23} \mathrm{~A}$ total of 20 larvae were incubated in EM alone (control) or EM with gentamicin $(300 \mu \mathrm{M})$ for $60 \mathrm{~min}$ for acute exposure, rinsed four times in fresh EM and then held to recover for $1 \mathrm{~h}$. Larvae were stained with the vital dyes YO-PRO-1 and DASPEI to estimate live hair cells in neuromaster. Larvae were exposed to EM containing $1 \mu \mathrm{M}$ YO-PRO-1 for $30 \mathrm{~min}$. YO-PRO-1-stained hair cells formed a line on the upper portion of neuromasts under fluorescent microscopy. DASPEI (Invitrogen) was also used for posttreatment labeling of hair cells. ${ }^{25}$ DASPEI was added to the last postgentamicin rinse at a final concentration of $0.005 \%$. Zebrafish were incubated for $15 \mathrm{~min}$, and then rinsed twice with fresh EM. Ten neuromasts from each larva (10-13 fish per treatment) were scored on a 0 (no/little staining), 1 (reduced staining) or 2 (normal staining) scale, resulting in a score of $0-20$ for each fish..$^{25,26}$ The DASPEI scores were averaged for each group and normalized as a percentage of vehicle-treated controls. In addition, larvae were immersed in GTTR $(400 \mu \mathrm{M})$ diluted in EM for $5 \mathrm{~min}$ at room temperature to examine the direct uptake of gentamicin into neuromast of zebrafish. The larvae were immobilized in a drop of $1.5 \%$ low-melt agarose. Then, neuromasts (SO1, SO2, IO1 and $\mathrm{IO} 2)^{19}$ were captured using a fluorescent microscope (X71, Olympus).

\section{Statistical analysis}

Each experiment was performed at least three times independently, and all values are presented as mean \pm s.d. of triplicates. A one-way analysis of variance was used to analyze the statistical significance. A $P<0.05$ was considered significant.

\section{RESULTS}

\section{Base-to-apex gradient hair cell damage caused by gentamicin}

Organ of Corti explants from four regions of P3 rat cochlea (apex, upper-middle, lower-middle and base) were treated with $300 \mu \mathrm{M}$ gentamicin for $24 \mathrm{~h}$. The explants were stained with phalloidin-TRITC (Figure 1Aa, b) and DAPI (Figure 1Ac, d) and observed under a fluorescent microscope. TRITCphalloidin-stained control explants exhibited a normal pattern of three OHC rows and a single row of IHCs (Figure 1Aa). All OHCs exhibited V-shaped stereocilia bundles and normal nuclei (Figure 1Aa, c). However, gentamicin exposure induced apparent stereocilia bundle damage. Interestingly, basal turn IHCs and OHCs showed the greatest degree of damage, 
A
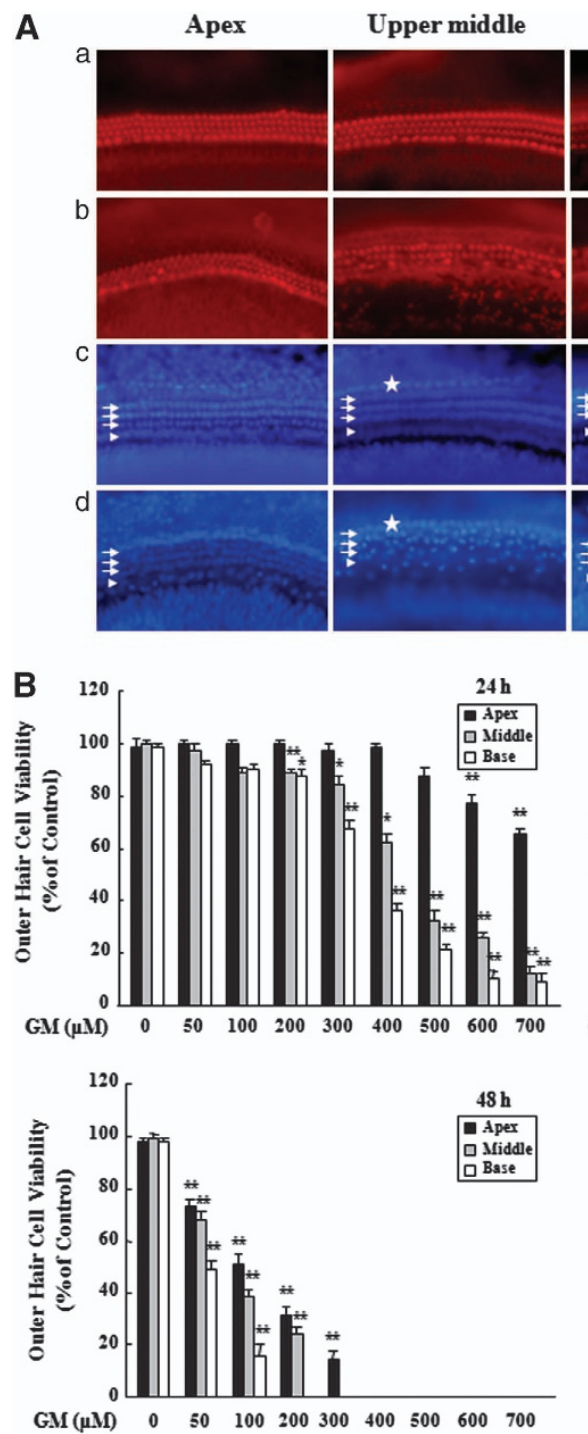
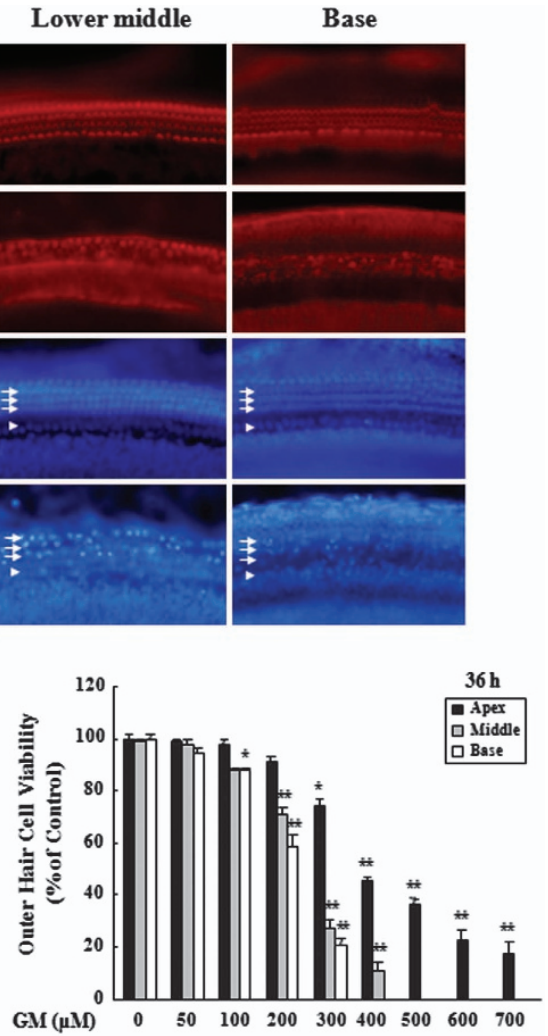

GM $(\mu M) \quad 0 \quad 50 \quad 100 \quad 200 \quad 300 \quad 400 \quad 500 \quad 600 \quad 700$

Figure 1 Hair cell death caused by gentamicin in a time- and dose-dependent manner. (A) Cochlear explant cultures from postnatal day 3 rats were maintained in the absence $(a, c)$ or presence $(b, d)$ of $300 \mu \mathrm{m}$ gentamicin for $24 \mathrm{~h}$. Cultures were stained with phalloidintetramethylrhodamine isothiocyanate (TRITC; a, b) and 4',6-diamidino-2-phenylindole (DAPI; c, d) and observed under a fluorescent microscope. Outer hair cells (OHCs): arrow, inner hair cells (IHCs): arrowhead, and Hensen's cells: star. (B) Quantitative analysis of OHC loss in explants treated for 24, 36 and $48 \mathrm{~h}$ with various doses (50, 100, 200, 300, 400, 500, 600 and $700 \mu \mathrm{m}$ ) of gentamicin. The percentage of hair cells missing at various gentamicin doses was significantly different from that of the control. Data are mean \pm s.d. of three samples. ${ }^{*} P<0.05$ and ${ }^{* *} P<0.01$ by one-way analysis of variance (ANOVA), compared with each turn of control group not treated with gentamicin.

followed by hair cells in the middle and apical turns (Figure1Ab). The nuclei of control IHCs and OHCs were round shaped, but the nuclei of gentamicin-exposed IHCs and OHCs were fragmented and disappeared (Figure 1Ac, d). This base-to apex gradient damage caused by gentamicin was further confirmed by treating the cochlear explants with 50-700 $\mu \mathrm{m}$ gentamicin for 24,36 and $48 \mathrm{~h}$. Intact hair cells were counted in a section corresponding to 10 IHCs at three different zones located on the apical, middle and basal turns of each organ of Corti. Hair cell survival decreased significantly after gentamicin exposure in a time- and dose-dependent manner (Figure 1B). We also observed base-to-apex gradient hair cell damage (Figure 1B).

\section{In vitro gentamicin uptake into cochlear explants}

Whole cochlear explants on a collagen matrix were treated with TR $(1.8 \mu \mathrm{M})$ or GTTR $(500 \mu \mathrm{M})$ for $30 \mathrm{~min}$ and fixed to directly observe in vitro gentamicin uptake. The explants were embedded in paraffin and cut into $4-\mu \mathrm{m}$-thick sections. For observing, specimens were deparaffinized and incubated with DAPI to observe nuclei. As shown in Figure $2 \mathrm{Ab}$, strong red fluorescence was observed in the IHCs and OHCs of 
A
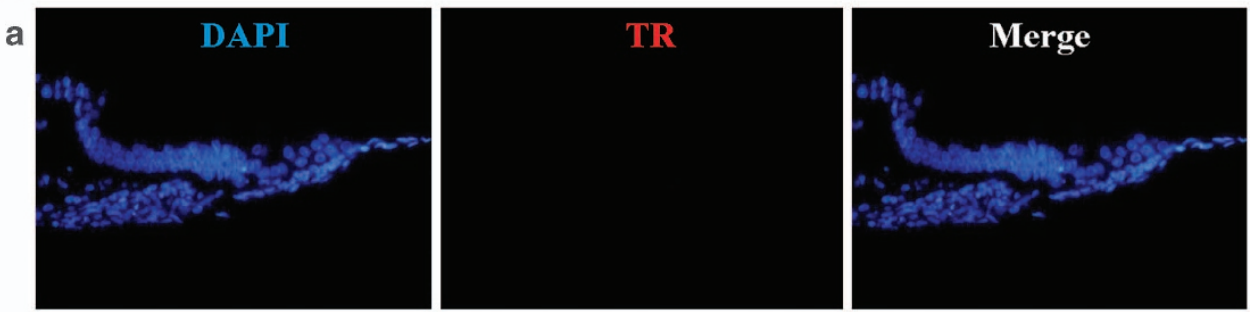

b
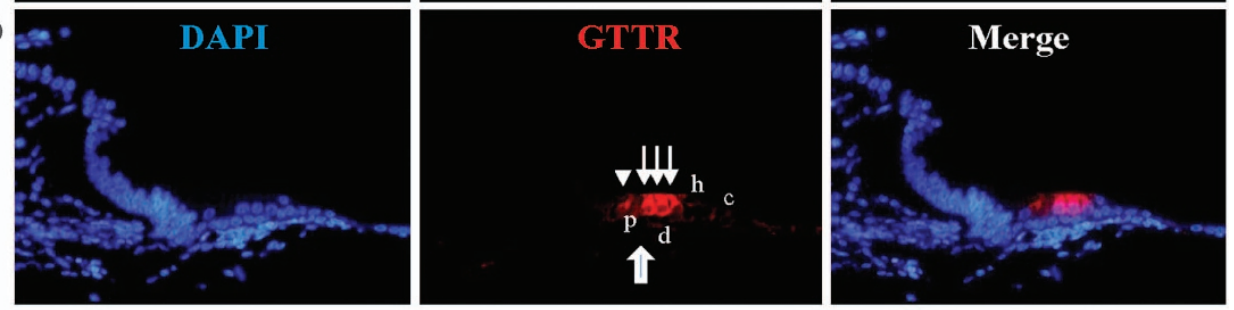

B
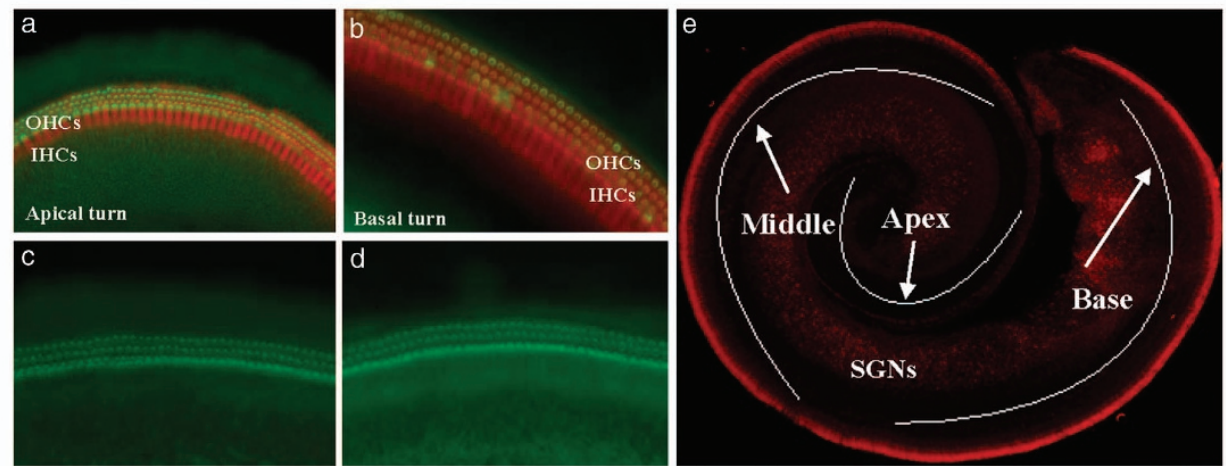

Figure 2 Distribution of gentamicin-conjugated Texas Red (GTTR) in cochlear explants after treatment in vitro. (A) Whole cochlear explants on a collagen matrix were treated with (a) Texas Red (TR; $1.8 \mu \mathrm{m}$ ) or (b) GTTR ( $500 \mu \mathrm{m}$ total including unconjugated gentamicin) for $30 \mathrm{~min}$ and fixed. The explants were embedded in paraffin and cut into 4- $\mu \mathrm{m}$-thick sections. Specimens were deparaffinized and incubated with 4',6-diamidino-2-phenylindole (DAPI) to observe the nucleus. Inner hair cells (IHCs) and outer hair cells (OHCs) displayed strong GTTR fluorescence intensity in the cytosol (IHCs: arrowhead, OHCs: arrow). Weak diffuse GTTR fluorescence was observed in the IHCs and OHCs nuclei. However, supporting cells displayed faint GTTR fluorescence intensity: Hensen's cell (h), cells of Claudius (c), Deiter's cells (d), pillar cells ( $p$ ) and basilar membrane (large arrow). (B) Cochlear explants were cultivated on cover glasses and treated for 30 min with $500 \mu \mathrm{m}$ GTTR (a, b, e), $1.8 \mu \mathrm{m}$ TR (c) and $500 \mu \mathrm{m}$ gentamicin plus $1.8 \mu \mathrm{m}$ TR (d). After fixation, the explants were stained with fluorescein isothiocyanate (FITC)-phalloidin (1:1000) and observed under a fluorescent microscope. Whole cochlear explants were obtained from postnatal day 3 (P3) rats to further examine this base-to-apex gradient of gentamicin uptake in cochlea (e). After removing the modiolus, the whole cochlear explant was incubated with $500 \mu \mathrm{m}$ GTTR for $120 \mathrm{~min}$. The specimens were observed under a fluorescent microscope after fixation.

GTTR-treated cochlear explants, but not in Texas-red-onlytreated explants (Figure 2Aa). Furthermore, fluorescence was also slightly detectable in the supporting cells, including Deiter's cells, inner and outer pillar cells, Hensen's cells and cells of Claudius (Figure 2A). Next, the explants prepared from the apex (a) and base (b, c and d) of the cochlea were incubated with GTTR, TR and gentamicin plus TR for $30 \mathrm{~min}$. After fixation, the explants were stained with FITC-phalloidin (1:1000) and observed under a fluorescent microscope. As shown in Figure 2Bc, d, TR fluorescence was not detected in hair cells of these two explants. Treatment with GTTR for 30 min did not damage the stereocilia bundles of the hair cells. In addition, strong GTTR fluorescence was present around the hair cell bodies. However, GTTR fluorescence intensity of hair cells in the basal turn (Figure $2 \mathrm{Bb}$ ) was stronger than that in the apical turn (Figure 2Ba). These results suggest that gentamicin was more preferentially engulfed by hair cells in the basal turn compared with those in the apical turn. Furthermore, gentamicin is more preferentially engulfed by hair cells compared with that of surrounding supporting cells. Whole cochlear explants were obtained from P3 rats to further examine this base-to-apex gradient of gentamicin uptake in the cochlea. Whole cochlear explants were incubated with GTTR for $30 \mathrm{~min}$ and fixed after removing the modiolus. Weak diffuse and punctuate GTTR fluorescence was observed in the IHCs and OHCs of the apical turn, whereas robust GTTR fluorescence was detected in hair cells of the basal turn (Figure 2Be). 


\section{In vivo GTTR uptake into the inner ear}

The P3 SD rats were injected subcutaneously with a single $300 \mathrm{mg} \mathrm{kg}^{-1}$ dose of GTTR or TR solution, and allowed to recover for $24 \mathrm{~h}$ to examine in vivo gentamicin uptake into the inner ear. Then, the inner ears were fixed in 4\% PFA overnight at $4{ }^{\circ} \mathrm{C}$, and the surface was prepared. Apical and basal turns of cochlear explants were stained with FITC-labeled palloidin for $30 \mathrm{~min}$. As shown in Figure $3 \mathrm{Ab}$, only faint diffuse and punctuate GTTR fluorescence was observed in apical turn hair cells. However, the intensity of GTTR fluorescence (Figure 3Ac) was much stronger in the plate of basal turn hair cells than that in hair cells of the apical turn (Figure 3A). In addition, intact stereocilia bundles of OHCs and IHCs were also clearly observed by FITC-labeled palloidin staining. These data showed that the red GTTR fluorescence was colocalized with FITC-palloidin fluorescence, indicating that gentamicin was more preferentially engulfed by cochlear hair cells. Next, other fixed inner ears were embedded in paraffin for sectioning. The $4-\mu \mathrm{m}$-thick sectioned specimens were stained with DAPI and examined under a fluorescent microscope. As shown in Figure 3Ba, b, GTTR fluorescence intensity of basal turn hair cells was much stronger than that in hair cells at the

A
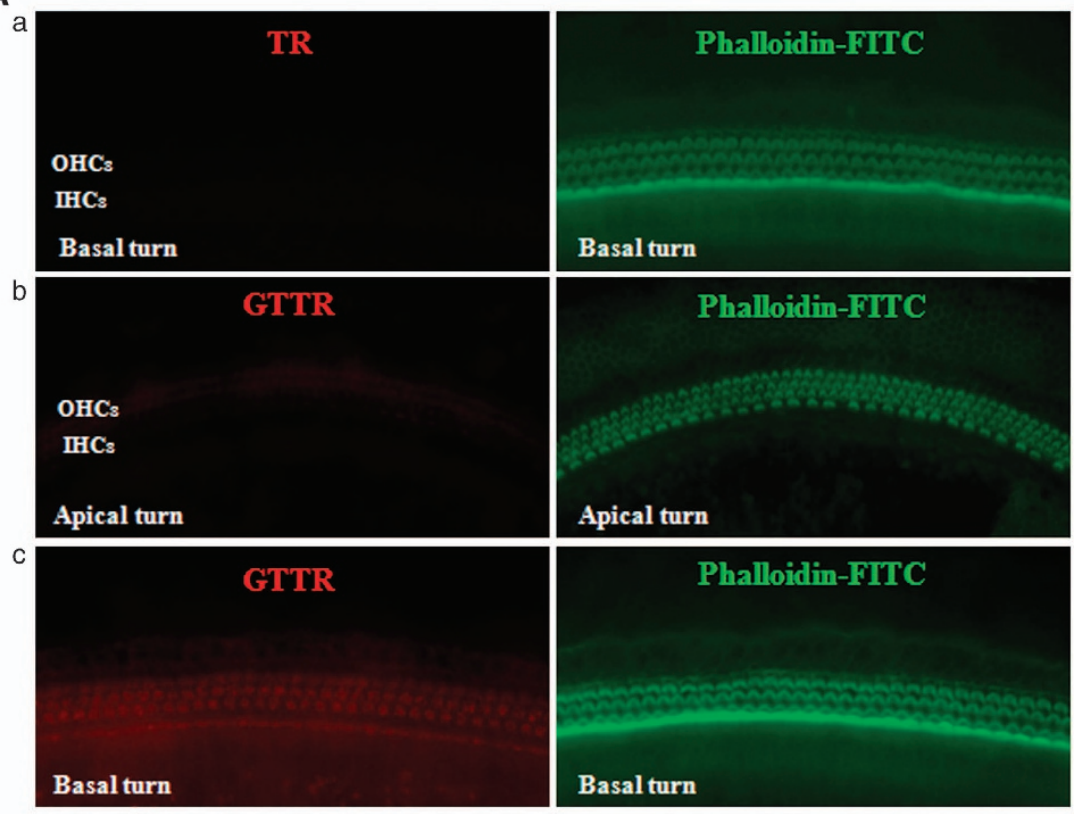

B
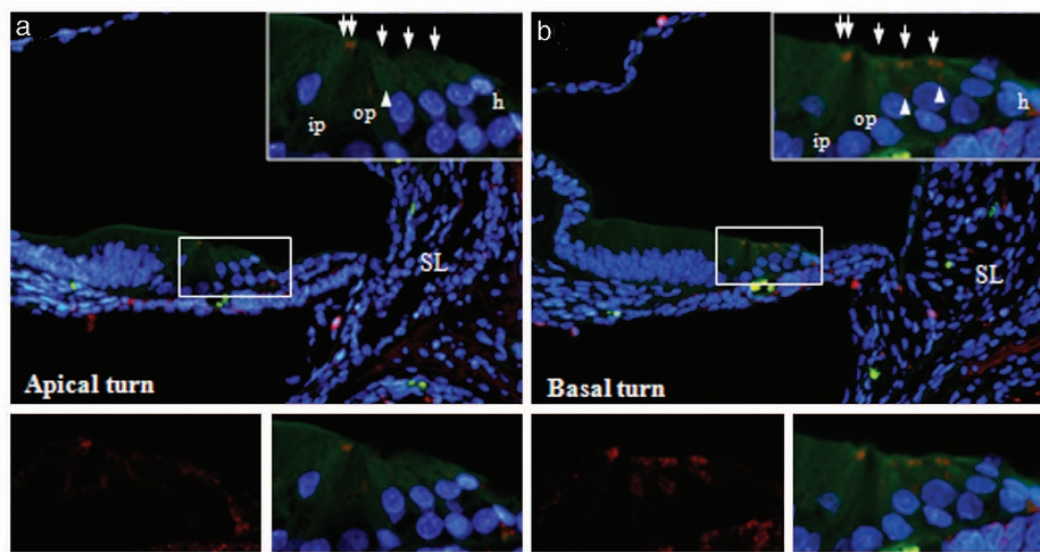

Figure 3 Distribution of gentamicin-conjugated Texas Red (GTTR) in the inner ear after in vivo injection. (A) Postnatal day 7 SpragueDawley rats were injected subcutaneously with a single $300 \mathrm{mg} \mathrm{kg}^{-1}$ dose of GTTR (b, c) or Texas Red (TR) solution (a) and then allowed to recover for $24 \mathrm{~h}$. Then, the temporal bones were prepared and fixed in $4 \%$ paraformaldehyde (PFA) overnight at $4{ }^{\circ} \mathrm{C}$. Apical and basal turns of cochlear explants were prepared and stained with fluorescein isothiocyanate (FITC)-labeled palloidin for 30 min, and specimens were observed under a fluorescent microscope. (B) The temporal bones were prepared from these rats and fixed in 4\% PFA overnight at $4{ }^{\circ} \mathrm{C}$. Next, the temporal bones were embedded in paraffin for sectioning at $4 \mu \mathrm{m}$ thickness. The sectioned specimens were stained with FITC-labeled phalloidin for $30 \mathrm{~min}$ and 4',6-diamidino-2-phenylindole (DAPI) for $10 \mathrm{~min}$ and examined under a fluorescent microscope. Inset shows punctuate GTTR staining observed in the cuticular plate of outer hair cells (OHCs) ${ }^{14}$ and inner hair cells (IHCs; double arrow), hair cell membrane (arrowhead), outer pillar cells (op), inner pillar cells (ip), Hensen's cells (h) and the spiral ligament (SL). 

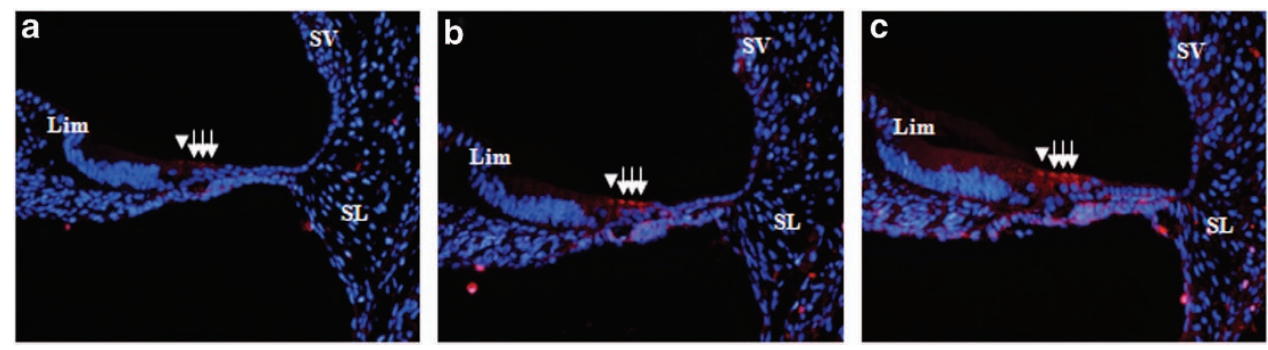

Figure 4 Gentamicin-conjugated Texas Red (GTTR) accumulation in the inner ear after consecutive in vivo injections. To further test whether GTTR accumulation in the inner ear is affected by the number of injections, postnatal day 3 Sprague-Dawley rats were injected subcutaneously with GTTR (300 $\mathrm{mg} \mathrm{kg}^{-1}$ per day) once (a), twice (b) or three times (c) and allowed to recover for $24 \mathrm{~h}$. Inner ears were fixed in paraformaldehyde (PFA) overnight at $4{ }^{\circ} \mathrm{C}$ and embedded in paraffin for sectioning at $4 \mu \mathrm{m}$ thickness. Specimens were stained with 4',6-diamidino-2-phenylindole (DAPI) and examined under a fluorescent microscope. IHCs are indicated by arrowhead and OHCs by arrow. IHCs, inner hair cells; Lim, spiral limbus; OHCs, outer hair cells; SL, spiral ligament; SV, stria vascularis.

apical turn. Negligible GTTR fluorescence was observed in many of the surrounding supporting cells, spiral ligament, stria vascularis and spiral ganglion neurons (Figure 3B).

The P3 SD rats were injected subcutaneously with GTTR (300 $\mathrm{mg} \mathrm{kg}^{-1}$ per day) once, twice or three times and allowed to recover for $24 \mathrm{~h}$ to further test whether GTTR accumulation in the inner ear was affected by the number of injections. Inner ears were fixed in PFA overnight at $4{ }^{\circ} \mathrm{C}$ and embedded in paraffin for sectioning at $4 \mu \mathrm{m}$ thickness. The specimens were stained with DAPI and examined under a fluorescent microscope. As shown in Figure 4, GTTR accumulation in the inner ear was amplified by increasing the number of injections. Interestingly, in contrast to preferential in vitro GTTR uptake by organ of Corti hair cells, in vivo GTTR uptake in other tissues including the spiral limbus, spiral ligament and stria vascularis was also observed (Figures $4 \mathrm{a}-\mathrm{c}$ ).

\section{Involvement of TRPV1 and TRPV4 channels in gentamicin} uptake into hair cells

TRP receptors are typical, nonselective calcium-permeant cation channels that transduce environmental stimuli. TRPV1 and TRPV4 modulate aminoglycoside uptake. ${ }^{11,12}$ Therefore, we examined whether TRPV1 and TRPV4 are expressed and involved in gentamicin uptake in the inner ear. TRPV1 and TRPV4 mRNA expression was clearly detected in all three parts, including the apex, middle and basal turns of the cochlea. Interestingly, TRPV1 mRNA expression in both the middle and basal turns was higher than that in the apex (Figure 5a). We performed immunofluorescence staining with anti-TRPV1 and anti-TRPV4 antibodies to further support the evidence of TRPV1 and TRPV4 protein expression in IHCs and OHCs. TRPV1 protein preferentially localized at the stereocilia. TRPV4 was detected at the stereocilia and the hair cell bodies (Figure 5b). Horizontal sections of paraffinembedded cochlea were stained with anti-TRPV1 and antiTRPV4 (Figure 5c). TRPV1 localized at the cuticular plate of IHCs and OHCs, including stereocilia and the hair cell body. TRPV4 was also detected in the hair cell body membranes. Notably, TRPV1 and TRPV4 protein expression was much higher in IHCs and OHCs of the basal turn than those of the apical turn. Next, we examined whether TRPV1 and TRPV4 expression is critically involved in gentamicin uptake by hair cells. Cochlear explants were treated with GTTR in the absence or presence of TRPV cation channel regulators such as gadolinium $\left(\mathrm{Gd}^{3+}\right)$ ions and ruthenium red $(\mathrm{RR}) \cdot \mathrm{Gd}^{3+}$ ions block calcium-permeant, mechanosensitive cation channels. $^{27-29} \mathrm{RR}$ is also a noncompetitive TRPV antagonist that blocks numerous cation channels. GTTR uptake was clearly observed in the absence of $\mathrm{Gd}^{3+}$ or RR. However, pretreatment with $\mathrm{Gd}^{3+}(50$ and $100 \mu \mathrm{M})$ or RR (10 and $50 \mu \mathrm{M})$ inhibited GTTR uptake in a dose-dependent manner (Figure 6a). We further confirmed that treatment with either $\mathrm{Gd}^{3+}$ or RR did not affect TRPV1 and TRPV4 protein expression (Figure 6b). Extracellular calcium desensitizes the TRPV1 channel, ${ }^{30}$ thereby reducing the movement of cations including gentamicin. ${ }^{11}$ Therefore, we tested whether changes in the extracellular calcium concentration might alter GTTR uptake from hair cells. GTTR uptake decreased markedly at calcium concentrations of $>1 \mathrm{~mm}$ (Figure 7a). Furthermore, hair cell damage caused by gentamicin in IHCs and OHCs was also clearly attenuated by calcium treatment (Figure 7b). However, the calcium treatment did not change TRPV1 and TRPV4 protein expression levels (Figure 7c).

\section{Effect of TRPV channel inhibitors on hair cell damage in neuromasts of GM-treated zebrafish}

Zebrafish have been extensively used as a model for assessing otototoxicity. ${ }^{31}$ At 5 day after fertilization, larvae were treated with $300 \mu \mathrm{M}$ gentamicin for $60 \mathrm{~min}$ and allowed to recover for $1 \mathrm{~h}$ in normal EM to evaluate gentamicin-induced death of hair cells in neuromasts of zebrafish. Then, the hair cells were labeled with YO-PRO-1 or DASPEI. As shown in Figure 8a, YO-PRO-1-stained hair cells in control neuromasts exhibited a normal conditioned state. However, hair cells treated with gentamicin showed significantly reduced cell survival. In addition, gentamicin exposure resulted in a reduced DASPEI score, indicating hair cell damage or loss (Figure 8b). Furthermore, GTTR uptake in hair cells of neuromasts was clearly attenuated by pretreatment with $\mathrm{RR}, \mathrm{Gd}^{3+}$ and $\mathrm{Ca}^{2+}$ (Figure 8c). 
a

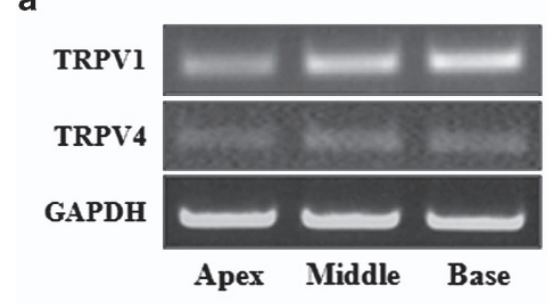

b

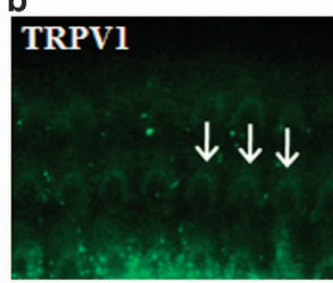

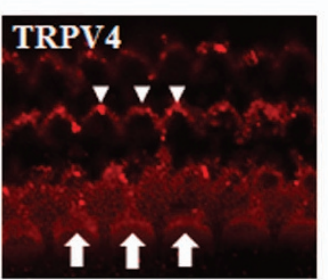

c
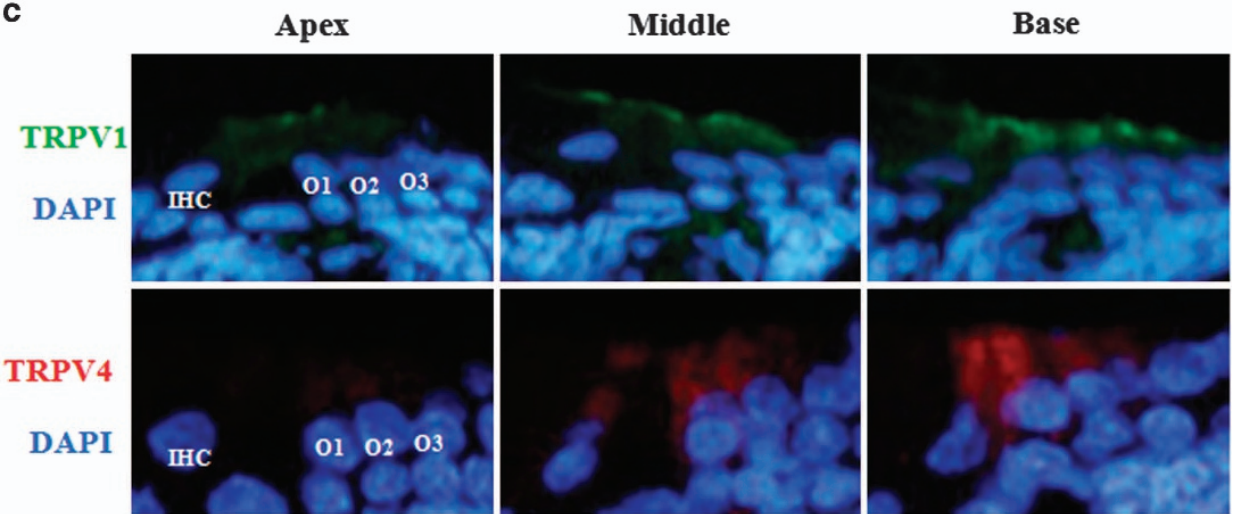

Figure 5 Expression and localization of transient receptor potential vanilloid 1(TRPV1) and TRPV4 in inner ear hair cells. (a) Total RNA was isolated from each turn of the cochlea, and complementary DNA (cDNA) was synthesized by reverse transcriptase-PCR (RT-PCR). The TRPV1 and TRPV4 genes were amplified with specific primer sets. GAPDH was used for coamplification of gene transcripts. (b) The stereocilia and bodies of hair cells were stained with anti-TRPV1 antibody ${ }^{14}$ or anti-TRPV4 antibody (arrowhead indicates outer hair cells (OHCs) and large arrow indicates inner hair cells (IHCs)) overnight at $4{ }^{\circ} \mathrm{C}$. Specimens were washed three times with Tris-buffered saline (TBS) plus $0.05 \%$ Tween-20 (TBS-T) and incubated with secondary antibodies for $1 \mathrm{~h}$ at room temperature in the dark. Alexa Fluor 488conjugated donkey anti-goat and Alexa Fluor 568-conjugated goat anti-rabbit were used as the secondary antibodies, respectively. (c) Horizontal tissue sections showing TRPV1 and TRPV4 immunofluorescence staining. Inner ears derived from postnatal day 3 SpragueDawley rats were fixed in paraformaldehyde (PFA) overnight at $4{ }^{\circ} \mathrm{C}$ and embedded in paraffin for sectioning at $4 \mu \mathrm{m}$ thickness. The specimens were stained with anti-TRPV1 or anti-TRPV4 antibodies and further stained with 4',6-diamidino-2-phenylindole (DAPI). These specimens were examined under a fluorescent microscope. 01, first layer of outer hair cells; 02, second layer of outer hair cells; 03, third layer of outer hair cells.

\section{DISCUSSION}

Gentamicin ototoxicity has remained a serious clinical problem since the $1960 \mathrm{~s},{ }^{32,33}$ and the mechanism of hair cell death caused by gentamicin still remains unclear. Aminoglycosides raise the intracellular calcium and reactive oxygen species levels in hair cells of inner ear and kidney cells..$^{9,34,35}$ They also lead to changes in cytoskeletal organization and cytochemical composition of hair cells, ${ }^{36,37}$ ultimately inducing the cell death pathway. However, a better understanding of gentamicin-induced ototoxicity is required to comprehend the uptake mechanisms in the inner ear. In this study, we investigated gentamicin ototoxicity in in vitro and in vivo model systems. The number of hair cells decreased in gentamicin-treated organ of Corti explants in a time- and dose-dependent manner. Hair cells at the base of the cochlea showed much greater preferential gentamicin uptake and were more susceptible to cytotoxicity than those of hair cells at the apex. In addition, the first row of OHCs exhibited severe damage, whereas the third row of OHCs exhibited moderate damage. The IHCs were more resistant to gentamicin than all three layers of the OHCs in the same organ of Corti region.
Earlier studies verified that OHC loss starts from the base of the cochlea and progresses toward the apex. ${ }^{1,2}$ One possible explanation for this finding is higher sensitivity of $\mathrm{OHCs}$ at the basal turn when compared with those at the middle and apical turns. Notably, levels of the reactive oxygen species scavenger glutathione at the apex are higher than those of OHCs at the base, ${ }^{4}$ indicating that the apex is intrinsically more resistant to free-radical insults than that of the base. Furthermore, Hayashida ${ }^{38}$ demonstrated that OHCs at the basal turn show preferential uptake of the aminoglycoside amikacin compared with those at the apical turn. This is also, in part, explained by the higher sensitivity of OHCs at the basal turn when compared with those at the middle and apical turns. Although we also showed that gentamicin uptake into OHCs increased from the apex to the base, our results were somewhat different from those of Hayashida ${ }^{38}$ with regard to the gentamicin uptake in IHCs. Hayashid ${ }^{38}$ reported that amikacin uptake decreases from the apex to the base, but gentamicin uptake into IHCs increased from the apex to the base in our in vitro and in vivo data. Although this discrepancy might be attributed to differences in the animal species used (guinea 
a

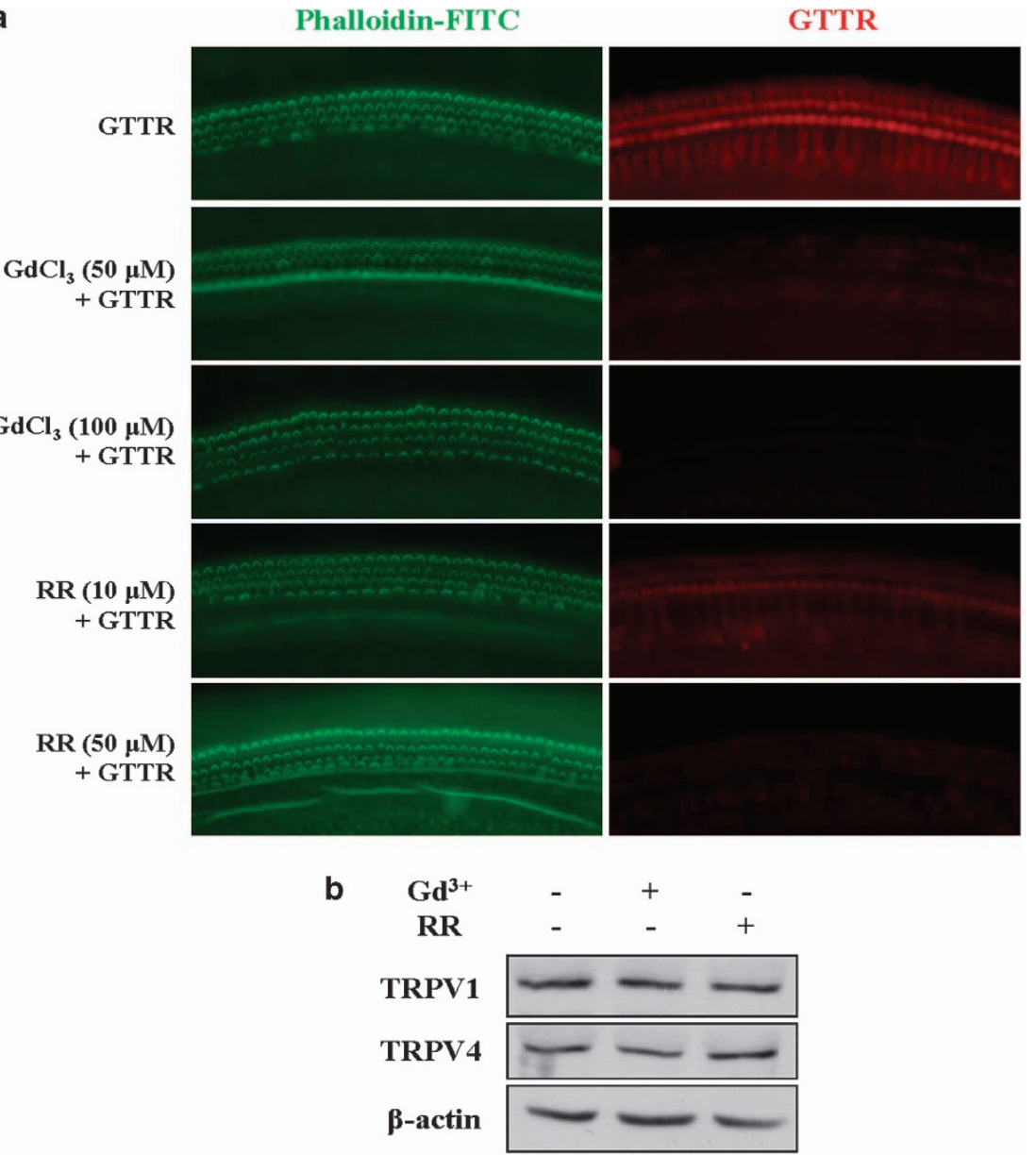

Figure 6 Modulation of gentamicin-conjugated Texas Red (GTTR) uptake in hair cells by gadolinium and ruthenium red (RR). (a) Cochlear explants were pretreated with gadolinium $(50 \mu \mathrm{m}$ and $100 \mu \mathrm{m})$ and RR (10 and $50 \mu \mathrm{m})$ for 30 min. Cochlear explants were fixed in $4 \%$ paraformaldehyde (PFA) and stained with phalloidin-fluorescein isothiocyanate (FITC) following treatment with $500 \mu \mathrm{m}$ GTTR for 30 min. The specimens were examined under a fluorescent microscope. (b) Cochlear explants were treated with gadolinium (100 $\mu \mathrm{m})$ and RR $(50 \mu \mathrm{m})$ for $12 \mathrm{~h}$. Total cell lysates of the organ of Corti were subjected to $8 \%$ sodium dodecyl sulfate-polyacrylamide gel electrophoresis (SDS-PAGE) and immunoblotted with transient receptor potential vanilloid 1 (TRPV1) and TRPV4 antibodies.

pig vs SD rats) or the aminoglycosides used (amikacin vs gentamicin), it must be resolved.

The gentamicin uptake mechanism remains unclear, but a long-standing hypothesis suggests that endocytotic uptake of aminoglycosides with processing through the Golgi bodies or lysosomes leads to hair cell death., ${ }^{5,739-44}$ However, more recent evidence suggests that aminoglycosides may enter hair cells via stereociliary mechanosensory transduction channels. ${ }^{45,46}$ GTTR has proven useful in studying endocytosis and trafficking of gentamicin. ${ }^{44,47}$ We observed in vitro and in vivo gentamicin uptake in OHCs, IHCs and other cells of the inner ear using GTTR. Our findings showed that the GTTR distribution increased from the apex to the base of the organ of Corti. Hair cells at the base were more susceptible to gentamicin than those at the apex, which might be related to the sequestration of gentamicin into those respective regions. The diffuse GTTR uptake in Deiter's cell and pillar cells after GTTR injection validated the observations of earlier studies. ${ }^{37,48,49}$ Pillar cells in guinea pigs are more susceptible to aminoglycoside toxicity than other supporting cells..$^{50}$ Furthermore, GTTR uptake in the stria vascularis also confirmed the findings of a previous report, ${ }^{37}$ suggesting either low levels of uptake or rapid extrusion. In the present study, GTTR uptake was low in the stria vascularis in vivo. Although it is not considered a primary target of aminoglycosides, the lateral wall and stria vascularis are subject to cytotoxicity only during chronic gentamicin treatment. ${ }^{51,52}$

All receptors in the growing TRP family are well documented as cation and transduction channels. TRP channels are only cation permeant; however, they also allow entry of larger molecules such as gentamicin. Our data provide evidence that fluorescence-labeled gentamicin entered cells via cation channels and that this penetration was mediated by TRPV1 and TRPV4 regulators. TRPV4 regulates cellular uptake of aminoglycoside antibiotics. ${ }^{12}$ We evaluated TRPV1 and TRPV4 expression in hair cells of the cochlea in vivo by 
a

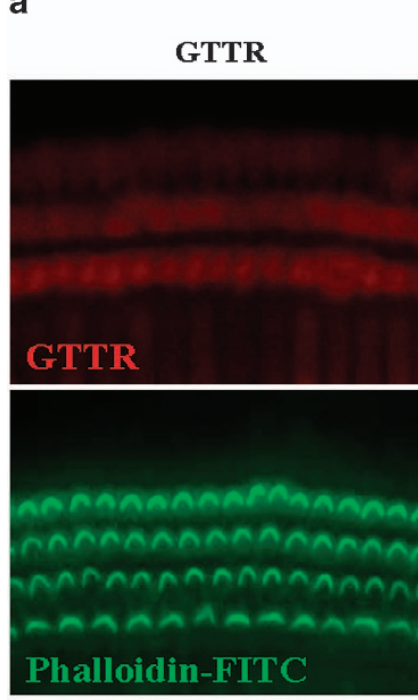

b
$\mathrm{Ca}^{2+}(1 \mathrm{mM})$ + GTTR
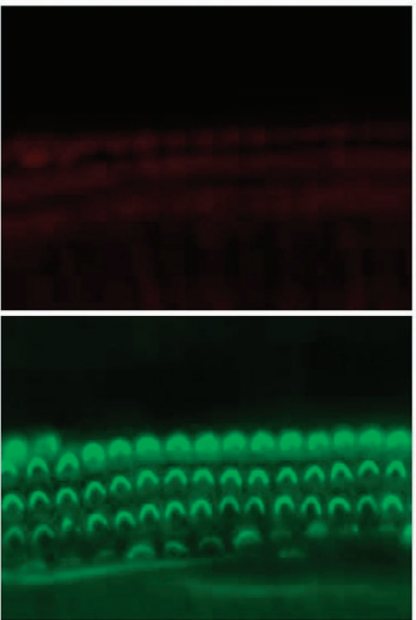

$\mathrm{Ca}^{2+}(2 \mathrm{mM})$ + GTTR
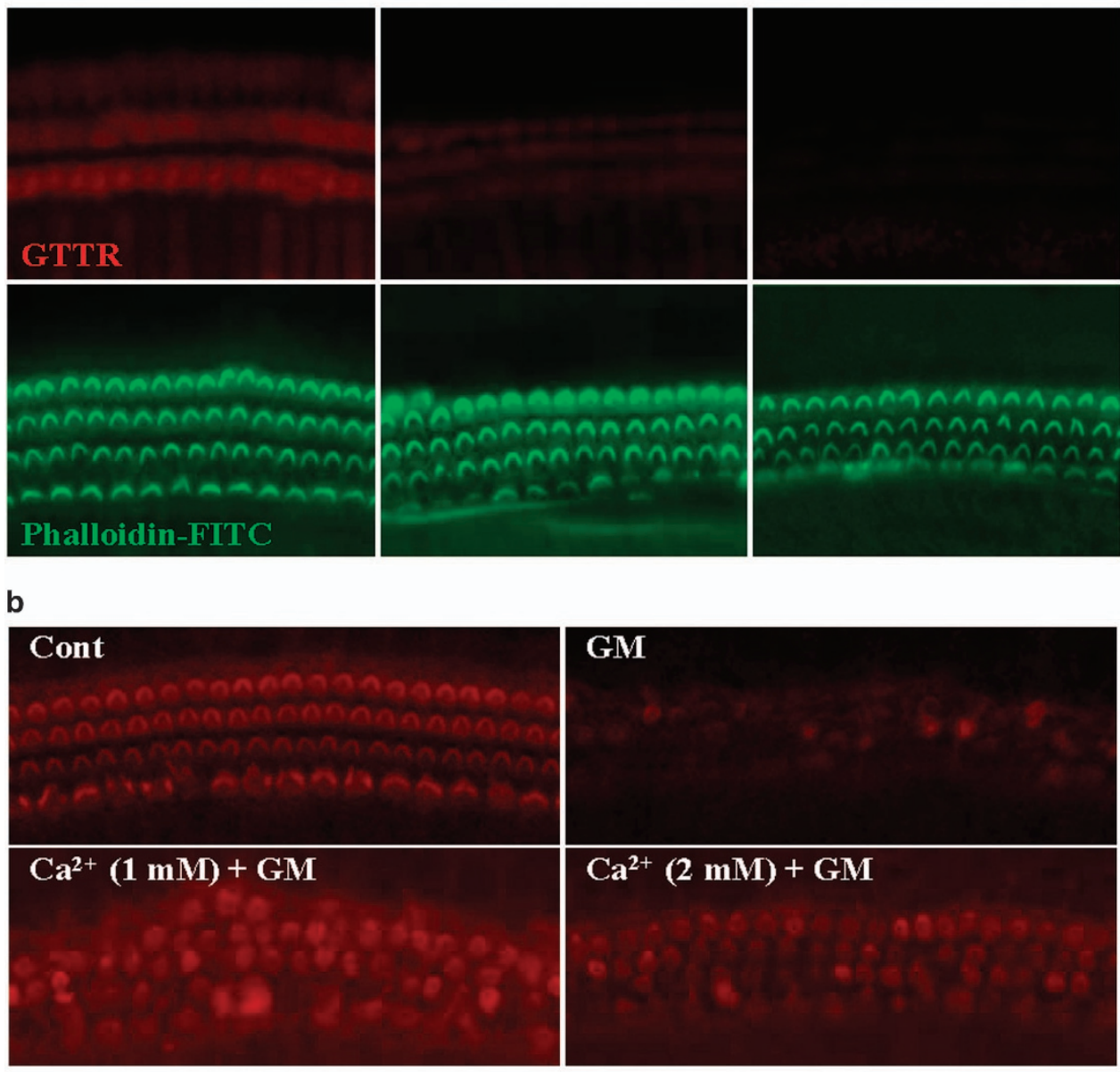

c

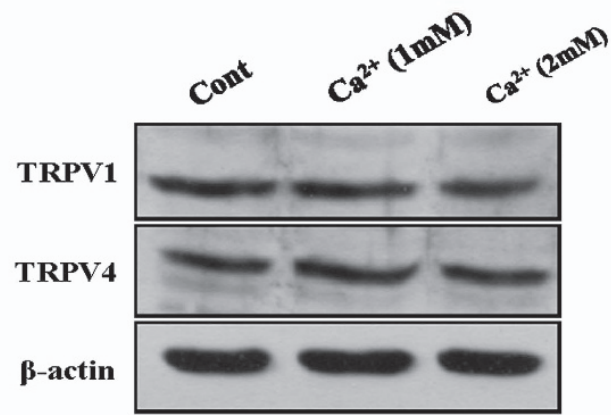

Figure 7 Modulation of gentamicin-conjugated Texas Red (GTTR) uptake and hair cell survival following exposure to calcium ions. Cochlear explants were pretreated with $\mathrm{Ca}^{2}+(1$ or $2 \mathrm{~mm}$ ) for $10 \mathrm{~min}$. (a) Cochlear explants were incubated with GTTR (500 $\mu \mathrm{m})$ for $30 \mathrm{~min}$ in the absence and presence of $\mathrm{Ca}^{2}+(1$ or $2 \mathrm{~mm})$. The samples were washed and fixed in $4 \%$ paraformaldehyde (PFA) and stained with fluorescein isothiocyanate (FITC)-labeled palloidin for $30 \mathrm{~min}$. The specimens were observed under a fluorescent microscope. (b) Cochlear explants were incubated with $300 \mu \mathrm{m}$ gentamicin for $24 \mathrm{~h}$ in the absence and presence of $\mathrm{Ca}^{2}+(1$ or $2 \mathrm{~mm})$. After fixation, the specimens were stained with phalloidin-tetramethylrhodamine isothiocyanate (TRITC) and examined under a fluorescent microscope. (c) Cochlear explants were incubated with or without $\mathrm{Ca}^{2+}(1$ or $2 \mathrm{~mm})$ for $12 \mathrm{~h}$. Cochlear explants treated with various $\mathrm{Ca}^{2}+$ concentrations were protected against gentamicin. Total cell lysates from the organ of Corti were subjected to $8 \%$ sodium dodecyl sulfate-polyacrylamide gel electrophoresis (SDS-PAGE) and immunoblotted with transient receptor potential vanilloid 1 (TRPV1) and TRPV4 antibodies.

immunohistochemistry. TRPV1 and TRPV4 were highly expressed in IHCs and OHCs of the basal turn compared with those of the apical turn. TRPV1 and TRPV4 protein expression also occurred in hair cell stereocilia. We found that the TRPV channel inhibitor RR significantly reduced GTTR uptake in vitro. As expected, GTTR uptake was also suppressed by $\mathrm{Gd}^{3}+$ because it has physiologically inhibited TRP channel function. ${ }^{27,28,53,54}$ In the present study, the dose-dependent 
a

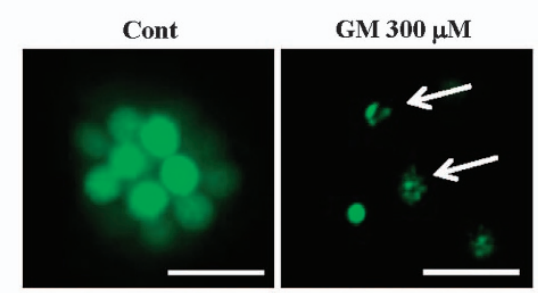

C
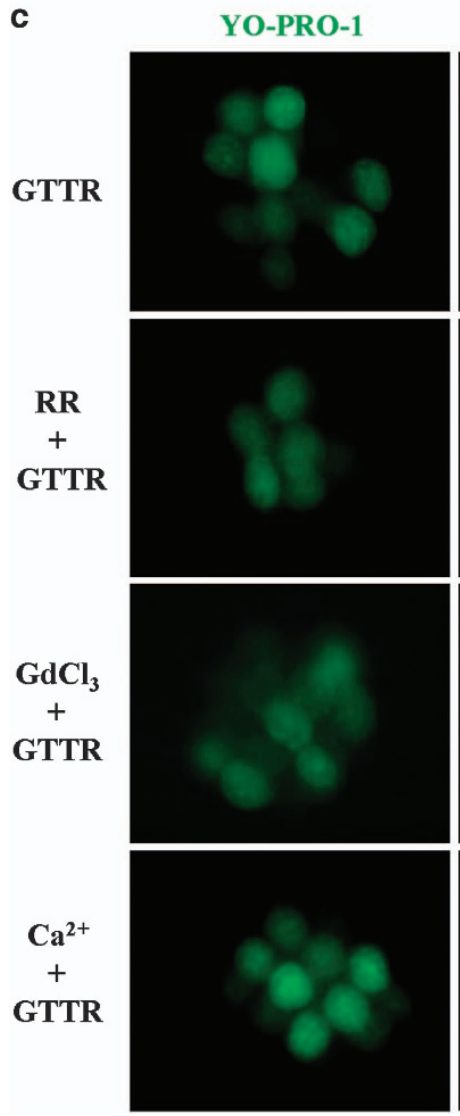

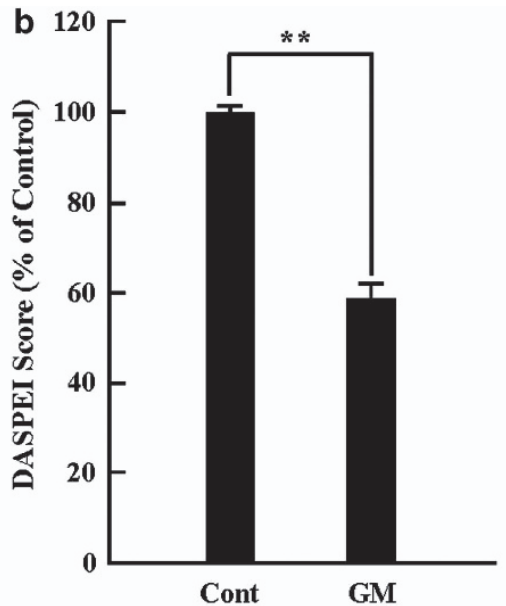

GTTR
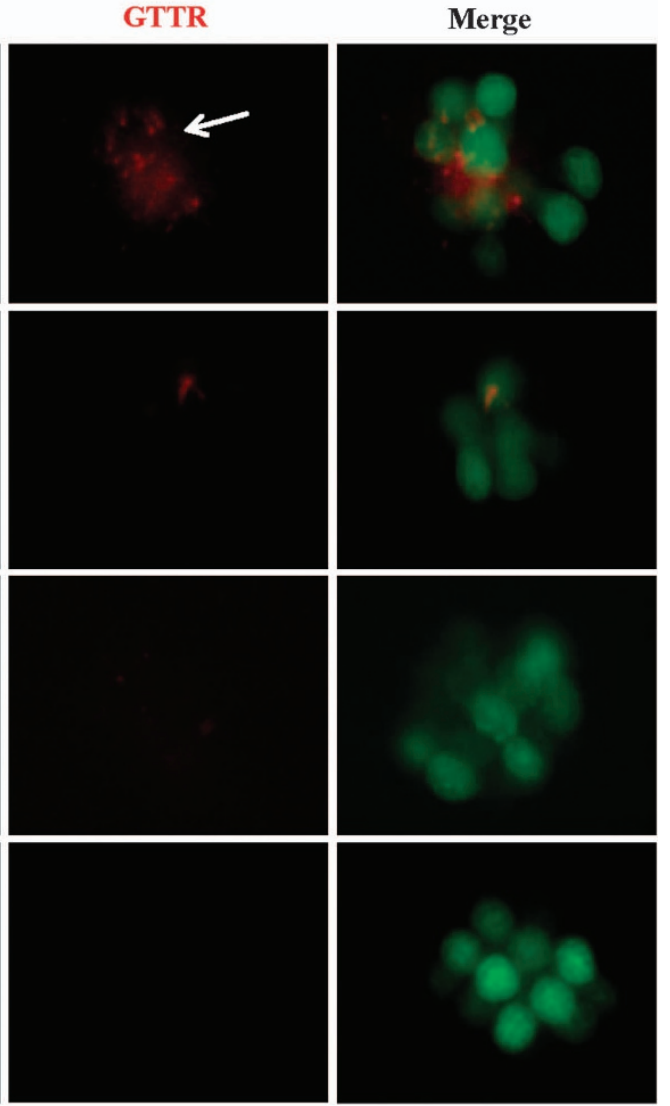

Figure 8 Effect of transient receptor potential vanilloid (TRPV) channel inhibitors on neuromast hair cell damage in gentamicin-treated zebrafish. At 5 day post fertilization (dpf), zebrafish larvae were treated with $300 \mu \mathrm{m}$ for $1 \mathrm{~h}$ and allowed to recover for $1 \mathrm{~h}$. (a) Hair cells labeled with YO-PRO-1. The scale bar in (a) is $5 \mu \mathrm{m}$ and applies to other panels also. (b) Hair cells are labeled with 2-(4(dimethylamino)styryl)- $N$-ethylpyridinium iodide (DASPEI). Mean hair cell survival was estimated using DASPEI scoring from 10 neuromasts per larvae $\left({ }^{* *} P<0.01\right.$, one-way analysis of variance (ANOVA)). (c) The $5 \mathrm{dpf}$, larvae were treated with $300 \mu \mathrm{m}$ gentamicinconjugated Texas Red (GTTR) for $15 \mathrm{~min}$ and allowed to recover for $30 \mathrm{~min}$. Then, larvae were further stained with YO-PRO-1 at $1 \mu \mathrm{m}$ for 30 min. Arrow in (c) indicates GTTR uptake in hair cells.

reduction of GTTR uptake by $\mathrm{Gd}^{3+}$ was confirmed in cochlear explants. These results demonstrate that gentamicin was contained by OHCs and IHCs through TRPV1 and TRPV4 channels. Finally, we tested whether GTTR uptake could be blocked by pharmacologically inhibiting TRPV1 and
TRPV4 in zebrafish hair cells. We observed that zebrafish neuromast hair cells deteriorated when treated with gentamicin, suggesting that zebrafish hair cells may share similar damage mechanisms as those of mammals. We showed that $\mathrm{Gd}^{3+}$ and $\mathrm{RR}$ inhibited gentamicin uptake in 
zebrafish hair cells. These findings are in agreement with the results derived from a gentamicin ototoxicity rodent model system.

We also found that external calcium reduced gentamicin uptake in mouse and zebrafish, consistent with the hypothesis that gentamicin uptake occurs through nonselective cationpermeant channels in the cytoplasm. ${ }^{55}$ Extracellular calcium desensitizes the TRPV1 channel and shortens the inward current induced by agonists. ${ }^{30,56}$ In addition, change in the external calcium concentration alters the kinetics of aminoglycoside entry through the transduction channel. ${ }^{57}$ It has also been shown that calcium modulates the uptake. ${ }^{58}$ Our data coincide with earlier observations, confirming that calcium reduces cation movement through TRPV1 channels.

In conclusion, the major finding of this study was that hair cells at the base of the cochlea were essentially able to take up more gentamicin than hair cells at the apex of the cochlea. Our results demonstrated that gentamicin uptake by hair cells occur through TRPV1 and TRPV4 channels. In addition, TRPV1 and TRPV4 expression in IHCs and OHCs at the basal turn was higher than that at the apical turn of the organ of Corti. These results suggest that the base-to-apex gradient damage to hair cells by gentamicin ototoxicity was, in part, attributed to the difference in gentamicin uptake by hair cells, where the cells were located at the basal or apical turn of cochlea. This difference in gentamicin uptake was attributed to the difference in TRPV1 and TRPV4 expression on hair cells.

\section{CONFLICT OF INTEREST}

The authors declare no conflict of interest.

\section{ACKNOWLEDGEMENTS}

This study was supported by a National Research Foundation of Korea (NRF) grant funded by the Korea government (MEST, no. 2011-0028866).

1 Forge A, Richardson G. Freeze fracture analysis of apical membranes in cochlear cultures: differences between basal and apical-coil outer hair cells and effects of neomycin. J Neurocytol 1993; 22: 854-867.

2 Kamimura T, Whitworth CA, Rybak LP. Effect of 4-methylthiobenzoic acid on cisplatin-induced ototoxicity in the rat. Hear Res 1999; 131: 117-127.

3 Richardson GP, Russell IJ. Cochlear cultures as a model system for studying aminoglycoside induced ototoxicity. Hear Res 1991; 53: 293-311.

4 Sha SH, Taylor R, Forge A, Schacht J. Differential vulnerability of basal and apical hair cells is based on intrinsic susceptibility to free radicals. Hear Res 2001; 155: 1-8.

5 Hashino E, Shero M. Endocytosis of aminoglycoside antibiotics in sensory hair cells. Brain Res 1995; 704: 135-140.

6 Hiel H, Bennani H, Erre JP, Aurousseau C, Aran JM. Kinetics of gentamicin in cochlear hair cells after chronic treatment. Acta Otolaryngol 1992; 112: 272-277.

7 Hashino E, Shero M, Salvi RJ. Lysosomal targeting and accumulation of aminoglycoside antibiotics in sensory hair cells. Brain Res 1997; 777: 75-85.

8 Mamdouh Z, Giocondi MC, Laprade R, Le Grimellec C. Temperature dependence of endocytosis in renal epithelial cells in culture. Biochim Biophys Acta 1996; 1282: 171-173.

9 Hirose K, Hockenbery DM, Rubel EW. Reactive oxygen species in chick hair cells after gentamicin exposure in vitro. Hear Res 1997; 104: 1-14.
10 Myrdal SE, Johnson KC, Steyger PS. Cytoplasmic and intra-nuclear binding of gentamicin does not require endocytosis. Hear Res 2005; 204: 156-169.

11 Myrdal SE, Steyger PS. TRPV1 regulators mediate gentamicin penetration of cultured kidney cells. Hear Res 2005; 204: 170-182.

12 Karasawa T, Wang Q, Fu Y, Cohen DM, Steyger PS. TRPV4 enhances the cellular uptake of aminoglycoside antibiotics. J Cell Sci 2008; 121: 2871-2879.

13 Fritzsch $\mathrm{B}$. The amphibian octavo-lateralis system and its regressive and progressive evolution. Acta Biol Hung 1988; 39: 305-322.

14 Kornblum HI, Corwin JT, Trevarrow B. Selective labeling of sensory hair cells and neurons in auditory, vestibular, and lateral line systems by a monoclonal antibody. J Comp Neurol 1990; 301: 162-170.

15 Higgs DM, Rollo AK, Souza MJ, Popper AN. Development of form and function in peripheral auditory structures of the zebrafish (Danio rerio). J Acoust Soc Am 2003; 113: 1145-1154.

16 Higgs DM, Souza MJ, Wilkins HR, Presson JC, Popper AN. Age- and sizerelated changes in the inner ear and hearing ability of the adult zebrafish (Danio rerio). J Assoc Res Otolaryngol 2002; 3: 174-184.

17 Gompel N, Cubedo N, Thisse C, Thisse B, Dambly-Chaudiere C, Ghysen A. Pattern formation in the lateral line of zebrafish. Mech Dev 2001; 105: 69-77.

18 Pichon F, Ghysen A. Evolution of posterior lateral line development in fish and amphibians. Evol Dev 2004; 6: 187-193.

19 Raible DW, Kruse GJ. Organization of the lateral line system in embryonic zebrafish. J Comp Neurol 2000; 421: 189-198.

20 Steyger PS, Peters SL, Rehling J, Hordichok A, Dai CF. Uptake of gentamicin by bullfrog saccular hair cells in vitro. J Assoc Res Otolaryngol 2003; 4: 565-578.

21 Gong X, Burbridge SM, Cowley EA, Linsdell P. Molecular determinants of $\mathrm{Au}(\mathrm{CN})(2)(-)$ binding and permeability within the cystic fibrosis transmembrane conductance regulator $\mathrm{Cl}(-)$ channel pore. J Physiol 2002; 540: 39-47.

22 Oh GS, Kim HJ, Choi JH, Shen A, Kim CH, Kim SJ et al. Activation of lipopolysaccharide-TLR4 signaling accelerates the ototoxic potential of cisplatin in mice. J Immunol 2011; 186: 1140-1150.

23 Whitlock KE, Westerfield M. The olfactory placodes of the zebrafish form by convergence of cellular fields at the edge of the neural plate. Development 2000; 127: 3645-3653.

24 Kimmel CB, Ballard WW, Kimmel SR, Ullmann B, Schilling TF. Stages of embryonic development of the zebrafish. Dev Dyn 1995; 203. 253-310.

25 Harris JA, Cheng AG, Cunningham LL, MacDonald G, Raible DW, Rubel EW. Neomycin-induced hair cell death and rapid regeneration in the lateral line of zebrafish (Danio rerio). J Assoc Res Otolaryngol 2003; 4: 219-234.

26 Owens KN, Cunningham DE, MacDonald G, Rubel EW, Raible DW, Pujol R. Ultrastructural analysis of aminoglycoside-induced hair cell death in the zebrafish lateral line reveals an early mitochondrial response. J Comp Neurol 2007; 502: 522-543.

27 Kondoh M, Kasai T, Shimada M, Kashiwayanagi M, Yokosawa H. cDNA cloning and characterization of an osmotically sensitive TRP channel from ascidian eggs. Comp Biochem Physiol B Biochem Mol Biol 2003; 134: 417-423.

28 Trebak M, Bird GS, McKay RR, Putney Jr JW. Comparison of human TRPC3 channels in receptor-activated and store-operated modes. Differential sensitivity to channel blockers suggests fundamental differences in channel composition. J Biol Chem 2002; 277: 21617-21623.

29 Urbach V, Leguen I, O'Kelly I, Harvey BJ. Mechanosensitive calcium entry and mobilization in renal A6 cells. J Membr Biol 1999; 168: 29-37.

30 Caterina MJ, Schumacher MA, Tominaga M, Rosen TA, Levine JD, Julius D. The capsaicin receptor: a heat-activated ion channel in the pain pathway. Nature 1997; 389: 816-824.

31 Buck LM, Winter MJ, Redfern WS, Whitfield TT. Ototoxin-induced cellular damage in neuromasts disrupts lateral line function in larval zebrafish. Hear Res 2011; 284: 67-81.

32 Hawkins Jr. JE, Johnsson LG, Aran JM. Comparative tests of gentamicin ototoxicity. J Infect Dis 1969; 119: 417-431.

33 Wersall J, Lundquist PG, Bjorkroth B. Ototoxicity of gentamicin. J Infect Dis 1969; 119: 410-416.

34 McLarnon S, Holden D, Ward D, Jones M, Elliott A, Riccardi D. Aminoglycoside antibiotics induce $\mathrm{pH}$-sensitive activation of the calcium-sensing receptor. Biochem Biophys Res Commun 2002; 297: 71-77. 
35 Staecker H, Kopke R, Malgrange B, Lefebvre P, Van de Water TR. NT-3 and/or BDNF therapy prevents loss of auditory neurons following loss of hair cells. Neuroreport 1996; 7: 889-894.

36 Furness DN, Hackney CM, Hynd AN. Rotated stereociliary bundles and their relationship with the tectorial membrane in the guinea pig cochlea. Acta Otolaryngol 1990; 109: 66-75.

37 Imamura S, Adams JC. Distribution of gentamicin in the guinea pig inner ear after local or systemic application. J Assoc Res Otolaryngol 2003; 4: 176-195.

38 Hayashida T. An immunohistochemical method for the study of aminoglycoside ototoxicity in the guinea pig cochlea using decalcified frozen sections. Arch Otorhinolaryngol 1989; 246: 161-164.

39 Ding D, Jin X, Zhao J. [Accumulation sites of kanamycin in cochlear basal membrane cells]. Zhonghua Er Bi Yan Hou Ke Za Zhi 1995; 30: 323-325.

40 Giuliano RA, Paulus GJ, Verpooten GA, Pattyn VM, Pollet DE, Nouwen EJ et al. Recovery of cortical phospholipidosis and necrosis after acute gentamicin loading in rats. Kidney Int 1984; 26: 838-847.

41 Gratacap B, Charachon R, Stoebner P. Results of an ultrastructural study comparing stria vascularis with organ of Corti in guinea pigs treated with kanamycin. Acta Otolaryngol 1985; 99: 339-342.

42 Hashino E, Shero M, Salvi RJ. Lysosomal augmentation during aminoglycoside uptake in cochlear hair cells. Brain Res 2000; 887: 90-97.

43 Sandoval R, Leiser J, Molitoris BA. Aminoglycoside antibiotics traffic to the Golgi complex in LLC-PK1 cells. J Am Soc Nephrol 1998; 9: 167-174.

44 Sandoval RM, Dunn KW, Molitoris BA. Gentamicin traffics rapidly and directly to the Golgi complex in LLC-PK(1) cells. Am J Physiol Renal Physiol 2000; 279: F884-F890.

45 Gale JE, Marcotti W, Kennedy HJ, Kros CJ, Richardson GP. FM1-43 dye behaves as a permeant blocker of the hair-cell mechanotransducer channel. J Neurosci 2001; 21: 7013-7025.

46 Kros CJ, Marcotti W, van Netten SM, Self TJ, Libby RT, Brown SD et al. Reduced climbing and increased slipping adaptation in cochlear hair cells of mice with Myo7a mutations. Nat Neurosci 2002; 5: 41-47.

47 Sandoval RM, Molitoris BA. Gentamicin traffics retrograde through the secretory pathway and is released in the cytosol via the endoplasmic reticulum. Am J Physiol Renal Physiol 2004; 286: F617-F624.

48 de Groot JC, Meeuwsen F, Ruizendaal WE, Veldman JE. Ultrastructural localization of gentamicin in the cochlea. Hear Res 1990; 50: 35-42.
49 von Ilberg C, Spoendlin H, Arnold W. Autoradiographical distribution of locally applied dihydrostreptomycin in the inner ear. Acta Otolaryngol 1971; 71: 159-165.

50 Ryan AF, Woolf NK, Bone RC. Ultrastructural correlates of selective outer hair cell destruction following kanamycin intoxication in the chinchilla. Hear Res 1980; 3: 335-351.

51 Forge A, Fradis M. Structural abnormalities in the stria vascularis following chronic gentamicin treatment. Hear Res 1985; 20: 233-244.

52 Forge A, Wright A, Davies SJ. Analysis of structural changes in the stria vascularis following chronic gentamicin treatment. Hear Res 1987; 31: 253-265.

53 Gillo B, Chorna I, Cohen H, Cook B, Manistersky I, Chorev M et al. Coexpression of Drosophila TRP and TRP-like proteins in Xenopus oocytes reconstitutes capacitative Ca2 + entry. Proc Natl Acad Sci USA 1996; 93: 14146-14151.

54 Walker RL, Koh SD. Sergeant GP, Sanders KM, Horowitz B. TRPC4 currents have properties similar to the pacemaker current in interstitial cells of Cajal. Am J Physiol Cell Physiol 2002; 283: C1637-C1645.

55 Hellwig N, Plant TD, Janson W, Schafer M, Schultz G, Schaefer M. TRPV1 acts as proton channel to induce acidification in nociceptive neurons. J Biol Chem 2004; 279: 34553-34561.

56 Mandadi S, Numazaki M, Tominaga M, Bhat MB, Armati PJ, Roufogalis $B D$. Activation of protein kinase $C$ reverses capsaicin-induced calciumdependent desensitization of TRPV1 ion channels. Cell Calcium 2004; 35: 471-478.

57 Marcotti W, van Netten SM, Kros CJ. The aminoglycoside antibiotic dihydrostreptomycin rapidly enters mouse outer hair cells through the mechano-electrical transducer channels. J Physiol 2005; 567: 505-521.

58 Coffin AB, Reinhart KE, Owens KN, Raible DW, Rubel EW. Extracellular divalent cations modulate aminoglycoside-induced hair cell death in the zebrafish lateral line. Hear Res 2009; 253: 42-51.

(c) (1) $\odot \Theta$ This work is licensed under a Creative Commons Attribution-NonCommercial-NoDerivs 3.0 Unported License. To view a copy of this license, visit http:// creativecommons.org/licenses/by-nc-nd/3.0/ 